\title{
Two Inbred Strains of Rats, Fischer 344 and Lewis, Showed Differential Behavior and Brain Expression of Corticosterone Receptor mRNA Induced by Methamphetamine
}

\author{
YOHTARO NUMACHI, ${ }^{a, c}$ SUMIKO YOSHIDA, ${ }^{b}$ SHIGENOBU TODA, ${ }^{a}$ \\ HIROO MATSUOKA, ${ }^{a}$ AND MITSUMOTO SATO ${ }^{a}$ \\ ${ }^{a}$ Department of Psychiatry, Tohoku University Graduate School of Medicine, \\ Sendai 980-8574, Japan \\ ${ }^{b}$ Mental Health Research Institute, University of Michigan, \\ Ann Arbor, Michigan 48109, USA
}

\begin{abstract}
Recently, a role of the hypothalamo-pituitary-adrenocortical (HPA) axis in facilitating the behavioral and neurochemical effects of psychostimulants has been proposed. Two inbred strains of rats, Fischer 344/N (F344) and Lewis/N (LEW), have markedly different HPA axes as well as behavioral responses to psychostimulants: F344 rats show hyperresponsive HPA axis and no significant sensitization to cocaine, whereas LEW rats display blunted response in HPA axis and develop cocaine-induced locomotor sensitization. Corticosterone exerts its biological effects via intracellular receptors, termed type I (mineralocorticoid receptor: MR) and type II (glucocorticoid receptor: GR). The present study examines the development of stereotypy sensitization and the brain expression of mRNAs for MR, GR, and heat shock protein 90 (HSP90) in methamphetamine (MAP)-treated F344 and LEW rats. Animals received i.p. injections with chronic saline (SAL: once daily for 21 days), chronic saline and acute MAP (AM: saline for 20 days and $4 \mathrm{mg} / \mathrm{kg}$ MAP on the 21st day), or chronic MAP (CM: $4 \mathrm{mg} / \mathrm{kg}$ MAP for 21 days) and were sacrificed three hours after the last injections. Striatum, hippocampus, and cerebellum were quickly dissected on ice and total RNA was isolated for northern analyses. LEW rats developed stereotypy sensitization significantly earlier than F344 rats. AM significantly decreased GR and MR mRNA expression in hippocampus of LEW, compared to SAL. CM significantly increased GR and MR mRNA expression in striatum of $\mathrm{F344}$ compared to $\mathrm{SAL}$ and $\mathrm{AM}$, while it decreased GR mRNA in striatum of LEW and MR mRNA in hippocampus, compared to SAL. AM significantly increased HSP90 mRNA in all brain regions examined, without the hippocampus in LEW. CM significantly increased the expression of HSP90 mRNA in the striatum and cerebellum of F344, but significantly decreased in the striatum and hippocampus of LEW. These contrasting differences between F344 and LEW, in their susceptibility to stereotypy sensitization and striatal expression of GR mRNA by chronic MAP, suggest that some striatal genes, whose transcription is regulated by GR, play a crucial role in the development of MAP-induced behavioral sensitization.
\end{abstract}

${ }^{c}$ Address for correspondence: Yohtaro Numachi, M.D., Ph.D., Department of Psychiatry, Tohoku University Graduate School of Medicine, Sendai 980-8574, Japan. Tel.: +81 22-717-7262; fax: +81 22-717-7266.

e-mail: ynumachi@psy.med.tohoku.ac.jp 


\section{INTRODUCTION}

Subchronic treatment of psychostimulants including amphetamine (AMP) and methamphetamine (MAP) to rodents often results in a progressive and long-lasting enhancement of stereotyped behavior elicited by a subsequent challenge injection of these drugs. These changes, termed behavioral sensitization, ${ }^{1}$ have been widely applied as a model for stimulant-induced psychosis as well as paranoid schizophrenia in humans. ${ }^{2}$ AMP and MAP are also known to cause hyperthermia in rats ${ }^{3,4}$ and mice. $^{5}$

Recently, a role of the hypothalamo-pituitary-adrenocortical (HPA) axis in facilitating the behavioral and neurochemical effects of psychostimulants has been proposed. Development of sensitization to amphetamine is prevented by administration of corticotropine-releasing hormone antibodies ${ }^{6}$ and also by adrenalectomy. ${ }^{7}$ Systemic administration of corticosterone sensitizes animals to the locomotor effects of AMP, ${ }^{8}$ whereas inhibition of corticosterone synthesis decreases cocaine-induced locomotion. ${ }^{9}$ These studies have suggested that corticosterone has a critical role in stimulant-induced behavioral sensitization.

Two inbred strains of rats, Fischer 344/N (F344) and Lewis/N (LEW), have markedly different HPA axes as well as behavioral responses to psychostimulants. LEW rats have blunted response in HPA axis and develop the gradual increase of locomotor activity typically seen following cocaine exposure, whereas F344 rats show hyperresponsive HPA axis and display no significant sensitization. ${ }^{10}$

Corticosterone exerts its biological effects via intracellular receptors, termed type I (mineralocorticoid receptor: MR) and type II (glucocorticoid receptor: GR), both of which act as ligand-activated transcription factors, binding to specific DNA sequences in the control region of target genes. ${ }^{11}$ The $90-\mathrm{kDa}$ heat shock protein (HSP90) functions as a molecular chaperone to prevent protein aggregation and assist refolding of denatured proteins. ${ }^{12}$ It also appears that HSP90 interacts with various proteins, including corticosterone receptors, protein kinases, and the $\beta \gamma$ subunits of $\mathrm{G}$ proteins to play a common role in the activity of diverse signaling systems. ${ }^{13,14}$ The present study examines the effects of acute and subchronic treatment of MAP on: (1) the development of stereotypy sensitization, (2) changes in body temperature, and (3) the brain expression of GR, MR, and HSP90 mRNAs, in F344 and LEW rats.

\section{MATERIALS AND METHODS}

\section{Animals and Drug Schedule}

Male Fischer 344/N (F344) and Lewis/N (LEW) rats, aged 7 weeks, 110-130 g (F344), 205-220 g (LEW) on arrival, were obtained from Funabashi Farm (Japan). Two or three animals were housed in a metal cage $(40 \times 35 \times 20 \mathrm{~cm})$ with free access to food (standard rat chow F-2, Funabashi Farm, Japan) and water, in a room maintained at $24 \pm 2{ }^{\circ} \mathrm{C}$ and $50 \pm 10 \%$ humidity under a $12 \mathrm{hr}$ light-dark cycle (lights on at 08:00 hr). We conducted all experiments under the guidelines of the animal ethics committee at the Tohoku University School of Medicine. 
F344 and LEW rats were each divided into three groups. One group received a daily intraperitoneal injection of $4 \mathrm{mg} / \mathrm{kg}$ MAP (saline solution) for 21 days during the light phase as chronic groups (FC and LC). The other groups received the same amount of saline intraperitoneally for 20 days, and $4 \mathrm{mg} / \mathrm{kg}$ MAP on the 21 st day during the light phase as acute groups (FA and LA). The last groups received the same amount of saline intraperitoneally for 21 days as control groups (FS and LS).

For FC and LC rats, changes in body temperature and stereotyped behavior were examined as follows. On the 1 st and 20th day, rectal temperatures were measured using a Digital Thermometer (PTC-201, JCS Unique Medicals Corp., Japan) at 0, 1, 2, and $3 \mathrm{hr}$ after injection. Stereotyped behavior was rated in the home cage at 0,1 , 2 , and $3 \mathrm{hr}$ after injection on the 1st, 7th, 14th, and 21st days, according to the scale by Creese and Iversen: ${ }^{15} 0$ ), asleep or stationary; 1 ), active; 2 ), predominantly active but with bursts of stereotyped sniffing or rearing; 3), stereotyped activity such as sniffing along a fixed path in the cage; 4), stereotyped sniffing or rearing maintained in one location; 5), stereotyped behavior in one location with bursts of gnawing or licking; 6), continual gnawing or licking of the cage bars.

\section{Total RNA Extraction and Northern Blot Analysis}

Three hr after the last injection, we sacrificed all rats by decapitation, quickly dissected caudate nuclei, hippocampus, and cerebellum on ice, and extracted total RNA from each sample by the guanidium thiocyanate method using RNAzol B (TELTEST Inc., TX, USA). About $20 \mu \mathrm{g}$ total RNA from each sample was subjected to formaldehyde-containing $1 \%$ agarose gel electrophoresis, and then transferred to nylon membrane (HyBond-N, Amersham, Bucks, UK) by capillary blot. The membranes were cross-linked by UV illumination for $3 \mathrm{~min}$, and prehybridized in a solution containing $50 \%$ formamide, $5 \times \mathrm{SSPE}, 2.5 \times$ Denhardt's solution, $1 \% \mathrm{SDS}$, $0.2 \mathrm{mg} / \mathrm{ml}$ denatured Salmon testes DNA at $42^{\circ} \mathrm{C}$ for $1 \mathrm{hr}$.

We conducted polymerase chain reaction (PCR) using rat hippocampal cDNA to generate a 405 bp cDNA fragment of the rat GR gene, ${ }^{16}$ a 404 bp cDNA fragment of the rat MR gene, ${ }^{17}$ a 489 bp cDNA fragment of the rat HSP90 gene, ${ }^{18}$ and a 378 bp cDNA fragment of the rat beta-actin gene. ${ }^{19}$ Oligonucleotide primers corresponding to nucleotides 361-386 and 739-765 for GR, nucleotides 932-958 and 1309-1335 for MR, nucleotides 331-357 and 793-819 for HSP90, and nucleotides 2494-2520 and 3052-3081 for beta-actin, were used for PCR, respectively. These cDNA fragments were subcloned into the pCR II vector with TA Cloning System (Invitrogen, CA, USA). We digested the clones by EcoRI to obtain cDNA probes, which were labeled with $\alpha-\left[{ }^{32} \mathrm{P}\right] \mathrm{dCTP}$ (Amersham, Bucks, UK) and Rediprime DNA labeling system (Amersham, Bucks, UK).

For Northern blot analysis, hybridization was performed with $1 \times 10^{6} \mathrm{cpm}$ of either GR, MR, or HSP90 cDNA probe/ml for $18 \mathrm{hr}$ at $42^{\circ} \mathrm{C}$. Blots were then washed for $15 \mathrm{~min}$ at $55^{\circ} \mathrm{C}$ in $0.4 \times$ sodium citrate (SSC) $/ 0.5 \%$ sodium dodecylsulfate (SDS), and washed for $15 \mathrm{~min}$ at $55^{\circ} \mathrm{C}$ in $0.2 \times \mathrm{SSC} / 0.5 \% \mathrm{SDS}$. After each hybridization the residual cDNA was removed and rehybridized with beta-actin cDNA probe, the results of which were used for standardization. Radioactivity associated with each hybridization signal was estimated by a Fujix Bio-Image Analyzer BAS2000 (Fuji Photo Film Co., Kanagawa, Japan). 


\section{Statistical Analysis}

The behavioral rating scores were analyzed using the Mann-Whitney U-test. Rectal temperature was analyzed by unpaired Student's $t$-test. Hybridization signals were analyzed by one-way analyses of variance (ANOVA) and, if significant, subsequent Scheffe's post hoc tests. In all cases, $p$ values less than 0.05 were considered statistically significant.

\section{RESULTS}

\section{Rectal Temperature}

FIGURE 1 shows rectal temperature in FC and LC rats on the 1st and 20th day of chronic MAP treatment. On the 1st day, MAP injection resulted in a significant elevation in rectal temperature in FC at 1 and $2 \mathrm{hr}$ after injection $(p<0.001, t$-test), which returned to normal at $3 \mathrm{hr}$. In LC, significant elevation in rectal temperature

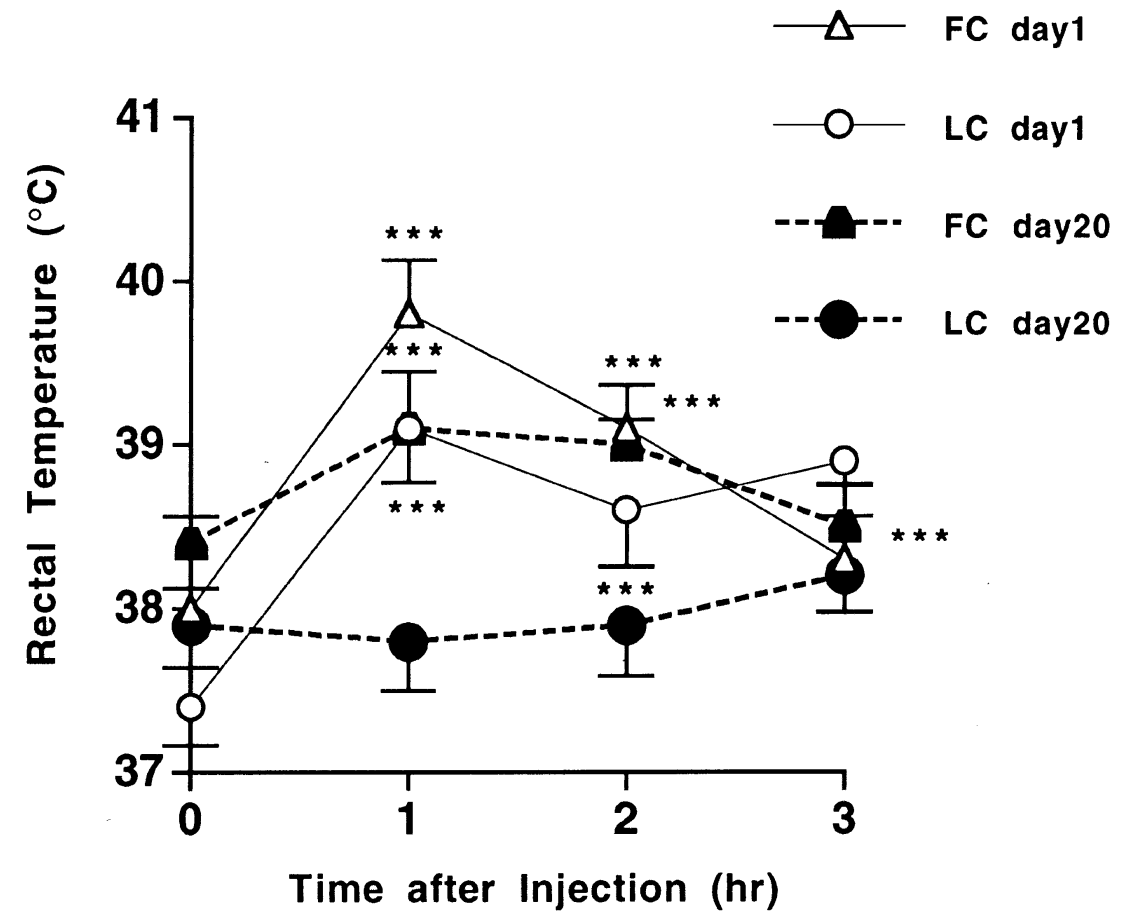

FIGURE 1. Time course of rectal temperature in F344 and LEW rats that received an intraperitoneal (i.p.) MAP injection ( $4 \mathrm{mg} / \mathrm{kg}$ ) for 21 days. Open triangles and circles represent rectal temperature of F344 and LEW on the 1st day of treatment, respectively. Closed triangles and circles represent rectal temperature of both strains on the 20th day of treatment, respectively. Each value is the mean $\pm \operatorname{SD}(n=6) . * * * p<0.001$; significantly different from $0 \mathrm{hr}$, $t$-test. 
was observed until $3 \mathrm{hr}(p<0.001, t$-test). On the 20th day, FC showed significant elevation in rectal temperature at 1 and $2 \mathrm{hr}(p<0.001, t$-test $)$, which returned to normal at $3 \mathrm{hr}$, while no significant hyperthermic effect of MAP was observed in LC.

\section{Behavioral Sensitization in Stereotypy}

F344 and LEW rats developed stereotyped behavior as a result of subchronic MAP treatment as shown in FIGURE 2. Behavioral sensitization was manifested as a significant increase in the stereotypy scores from the first MAP treatment after the 7 th day for LEW, and 14th for F344, respectively $(p<0.005)$. Stereotypy scores were significantly higher in LEW rats than in F344 rats on 7 th and 14 th day $(p<0.01)$. However, both strains ultimately plateaued at the same stereotypy rating score on the 21st day.

\section{Methamphetamine-induced GR, MR, and HSP90 mRNA Expression}

An approximately 7 kb GR mRNA, 6 kb MR mRNA, 2.9 kb HSP90 mRNA, and $2 \mathrm{~kb}$ beta-actin mRNA, corresponding to previous reports, ${ }^{20,21}$ were identified by Northern blot analysis. FIGURE 3 shows alterations in HSP90 mRNA (standardized by beta-actin mRNA) induced by acute or chronic MAP administration in the striatum, hippocampus, and cerebellum of F344 and LEW, respectively. Acute MAP treatment significantly increased HSP90 mRNA in all brain regions examined, without the hippocampus in LEW. By chronic MAP administration, HSP90 mRNA was significantly increased in the striatum and cerebellum of F344, but significantly decreased in the striatum and hippocampus of LEW, compared to saline control. FIGURE 4 illustrates striatal, hippocampal, and cerebellar GR and MR mRNA in F344 and LEW rats by acute or chronic MAP treatment, respectively (standardized by beta-actin mRNA). Acute MAP treatment significantly decreased hippocampal GR and MR mRNA expression in LEW, compared to saline control. Chronic MAP treatment significantly increased striatal and cerebellar GR and MR mRNA in F344 compared to control, while it significantly decreased striatal GR and MR mRNA and hippocampal MR mRNA in LEW compared to control.

\section{DISCUSSION}

Consistent with previous reports, ${ }^{4,5}$ on the 1 st day of chronic MAP treatment, hyperthermia was observed by $1 \mathrm{hr}$ after injection in F344 and LEW. Hyperthermic effects of MAP were still observed on the 20th treatment day in F344, while LEW showed no changes in body temperature. These results suggest that LEW acquired tolerance in hyperthermic effect of MAP during chronic treatment, but F344 did not. MAP has hyperthermic effect in rodents, possibly mediated by central dopamine. ${ }^{22}$ It has been suggested that the hyperthermic effect of MAP is regulated via mesolimbic dopaminergic (DAergic) pathway to the body temperature pivot in hypothalamus, since MAP-induced hyperthermia in mice is prevented by the DA D2 receptor antagonist, haloperidol. ${ }^{23}$ Differential responses between F344 and LEW in their body temperature to chronic MAP might be related to MAP-induced functional change in the mesolimbic DAergic system. 

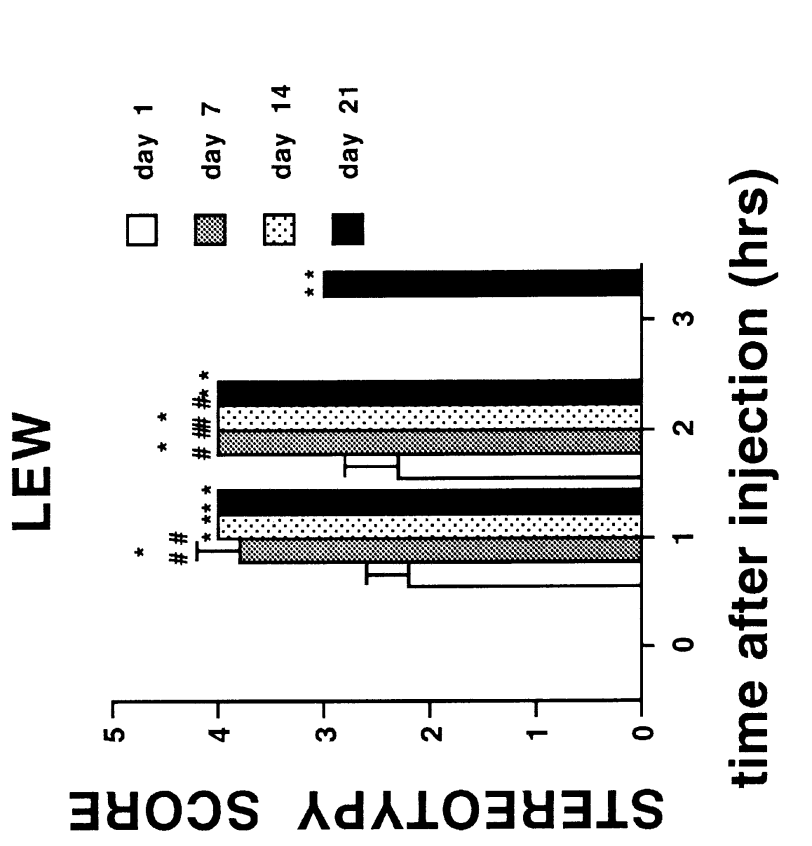

悉离至

过焉

$\sum_{0,0} \bar{c} \overline{0}$

bo

于.

政

.

$\exists$ : $\dot{0}$

*

ते

की 11

उ

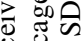

过

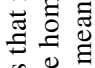

范焉过

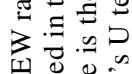

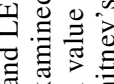

政

声焉

$\Xi$ 党

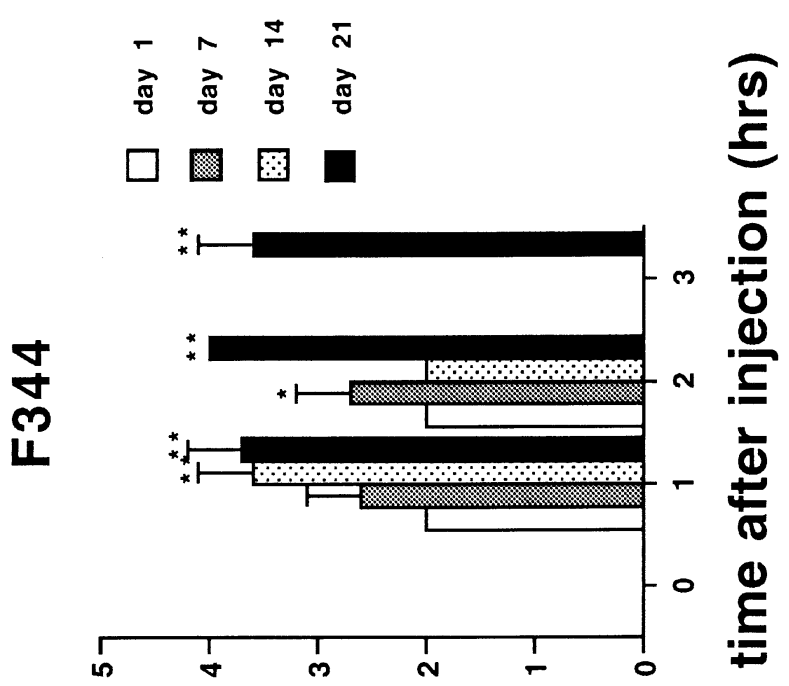

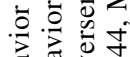

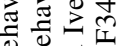

\&

o

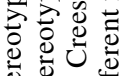

的合冓

엉 월

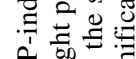

<

$\sum 000$

응ㅎㅎㅇ

吾

을

可 吾

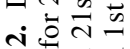




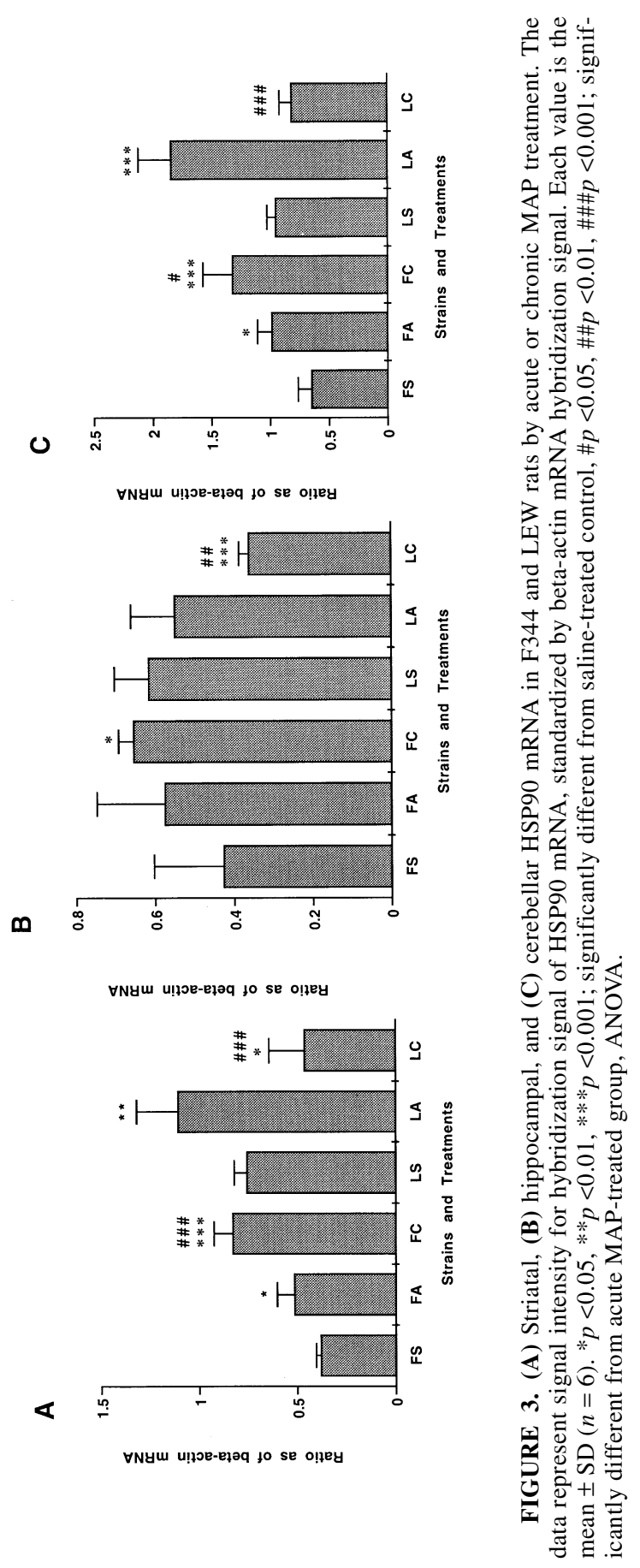




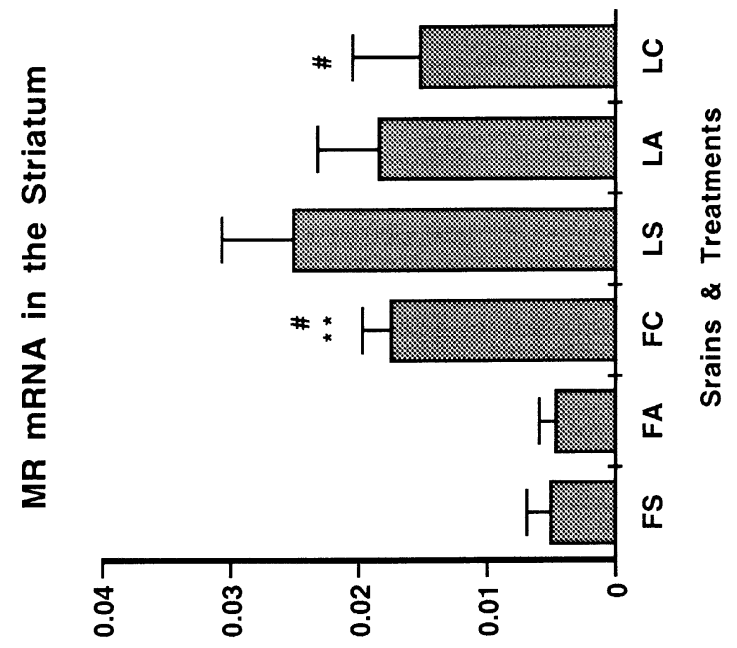

$\forall$ NYu U!łoe-eləq to se o!ley

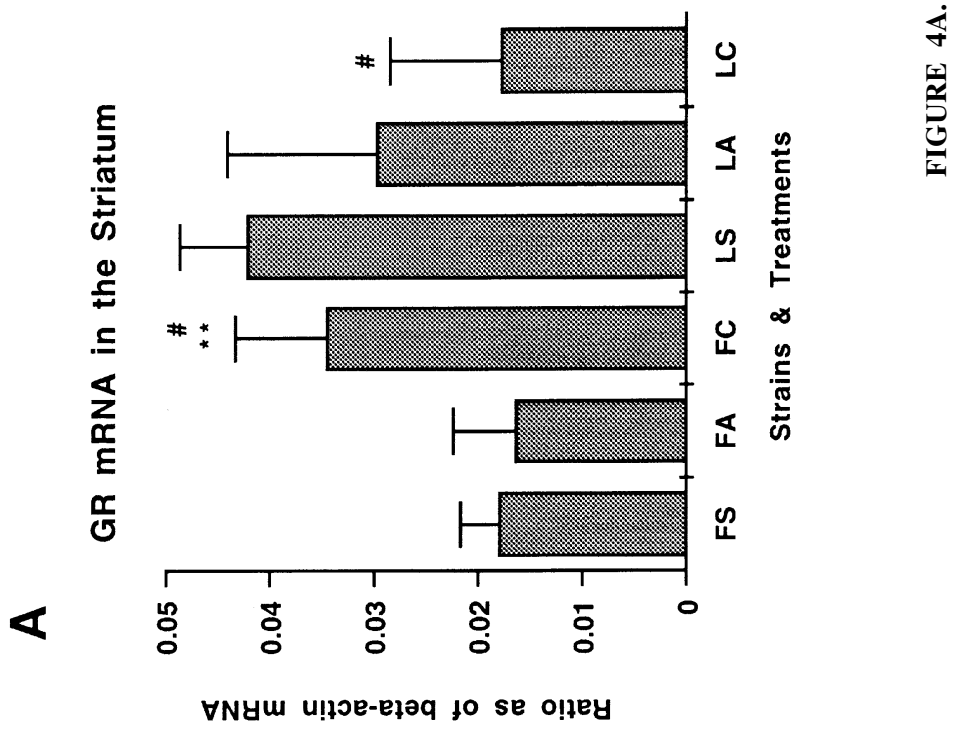




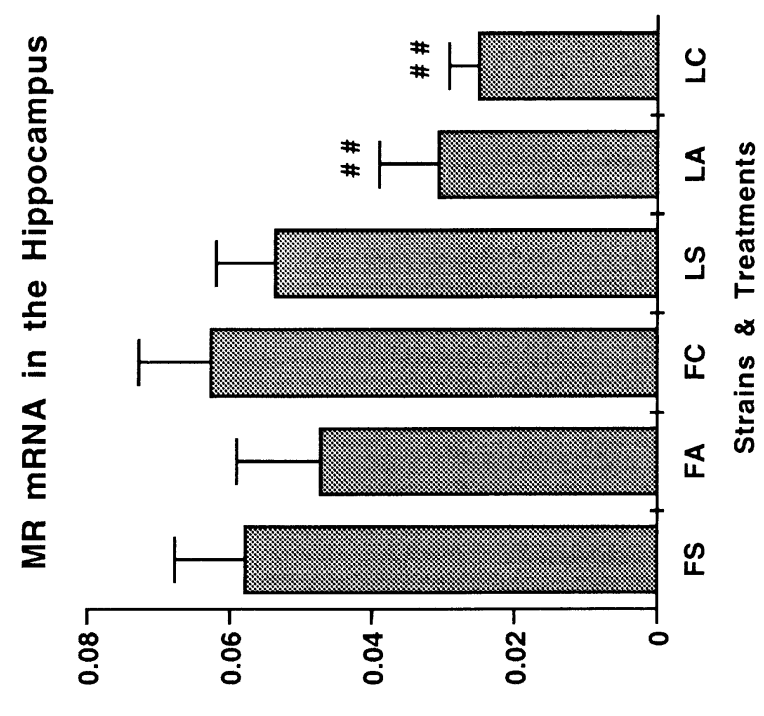

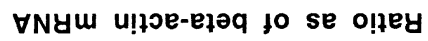

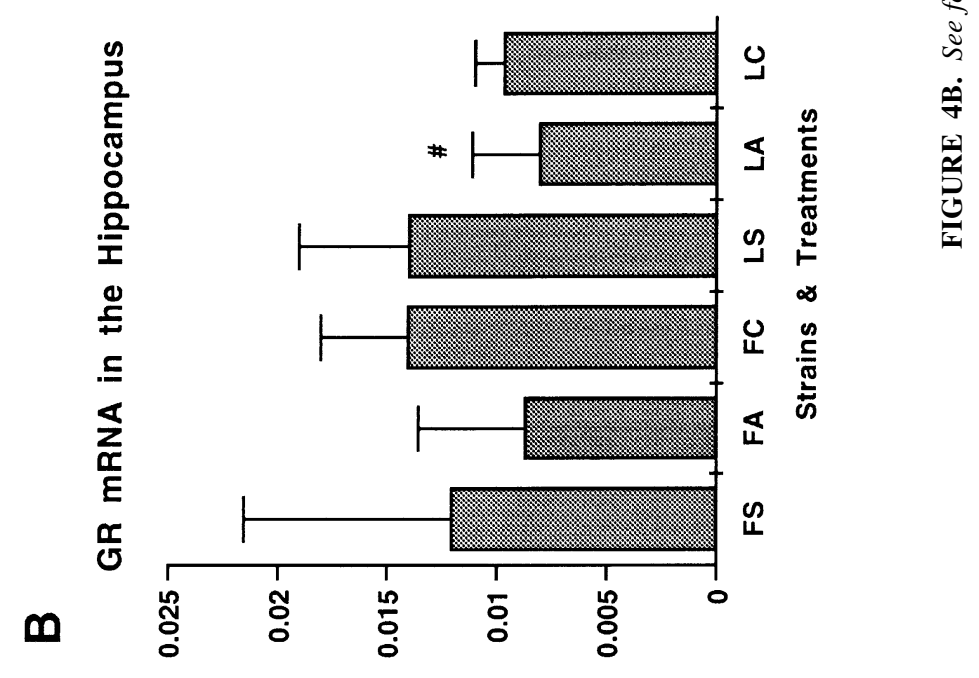

$\forall$ Nym U!łoe-ełəq to se o!̣ey 


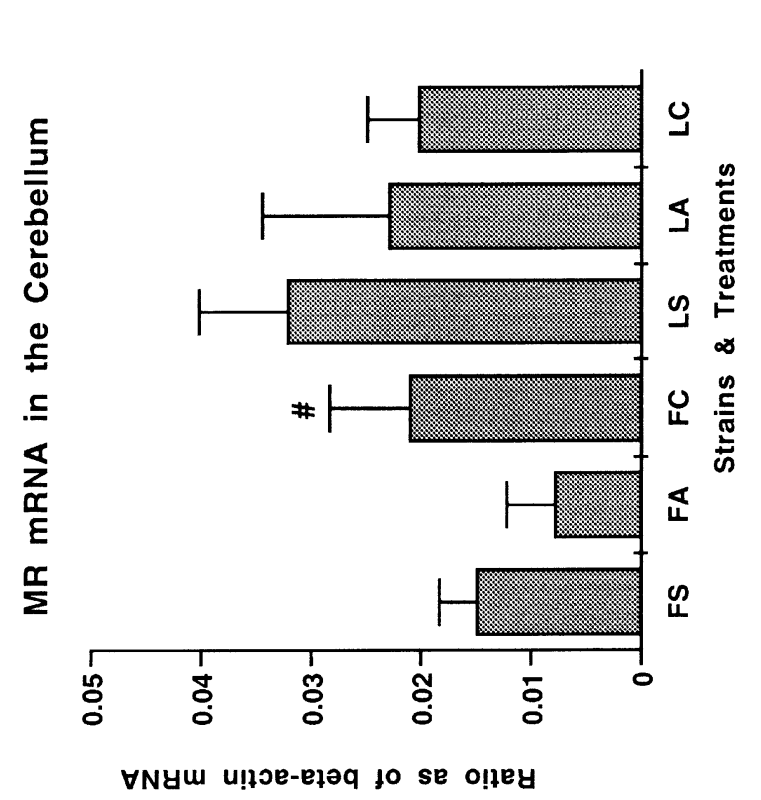

范要

要通施

可渮

远

.

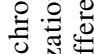

$t: 0$

0

氖

子̇ษ

胥

z罗落

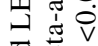

$\overrightarrow{0}=$

字酧

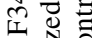

$\Xi \because \overline{0}$

范焉

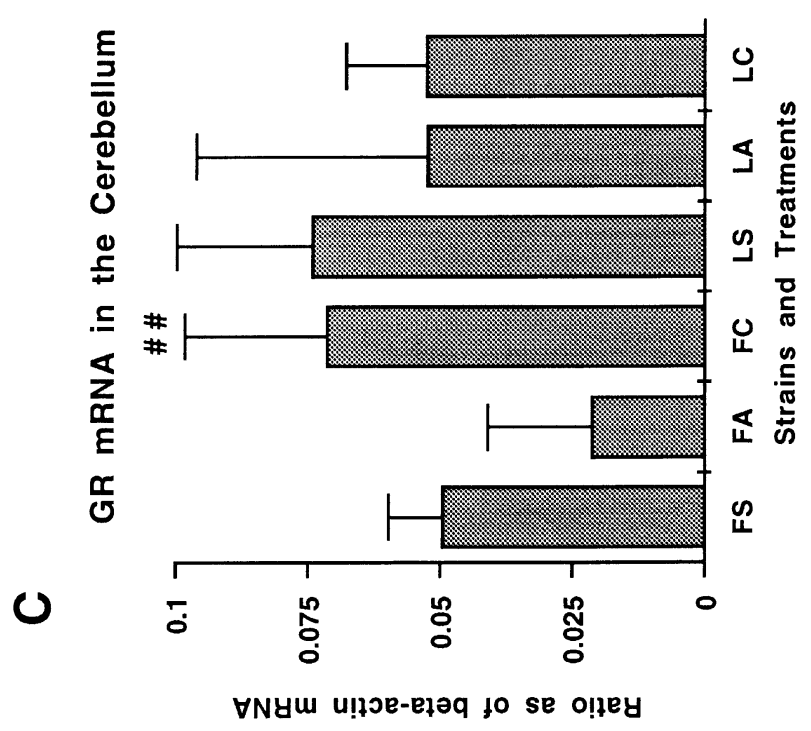

幽.

$\sum z$

政

앙료

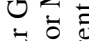

壱

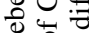

흔

(0)

흐음

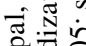

ह

난

产点丳

을

哥.

E。

.

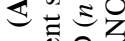

+ 的

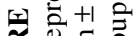

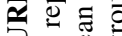

覀

正焉窇 
The hybridization signal of HSP90, GR, or MR mRNA was normalized relative to the signal obtained from beta-actin mRNA, whose expression was not affected by any dose of MAP. ${ }^{24}$ Acute MAP treatment significantly increased HSP90 mRNA in all brain regions examined, except for the hippocampus in LEW. This result was consistent with the report that a single injection of AMP increased the expression of HSP90 mRNA in whole brain, ${ }^{25}$ and also supported the previous reports that MAP and $\mathrm{AMP}^{3}$ induce the expression of HSP70 mRNA in the central nervous system. Increased brain expression of HSP90 mRNA by acute MAP, in both strains, might be due to MAP-induced hyperthermia.

Chronic MAP significantly increased the striatal and cerebellar HSP90 mRNA in F344, which is consistent with elevation in body temperature. However, striatal and hippocampal expression of HSP90 mRNA in LEW was significantly decreased by chronic MAP, in spite of no change in body temperature. HSP90 is believed to regulate the function of corticosterone receptors. In yeast with reduced HSP90 expression, corticosterone receptors failed to enhance transcription. ${ }^{26}$ The precise function of HSP90 and the reason for the MAP-induced decrease in HSP90 mRNA in LEW remain unclear. Further work is necessary to understand the mechanism of differences between F344 and LEW in brain expression of HSP90 mRNA by chronic MAP.

LEW rats developed MAP-induced stereotypy sensitization significantly earlier than F344 rats, as is consistent with our previous findings. ${ }^{27}$ Our result is also consistent with previous reports that LEW rats demonstrated greater locomotor sensitization than $\mathrm{F} 344$ rats as a result of $\mathrm{AMP}^{28}$ or cocaine ${ }^{10}$ administration. However, both F344 and LEW rats reached the same plateau of stereotypy sensitization, which reflects hyperactivity in the nigrostriatal DAergic pathway. The result that LEW did not acquire tolerance in stereotypy sensitization suggests that effects of MAP on the nigrostriatal and the mesolimbic DAergic systems are differentially regulated in F344 and LEW.

Acute administration of AMP or cocaine is known to elevate the level of corticosterone in male Wister rats for $2 \mathrm{hr}^{29}$ In LEW, because of blunted negative feedback in the HPA axis, acute and chronic MAP treatment may cause long-lasting elevation in corticosterone level. On the other hand, duration of MAP-induced elevation in corticosterone may be much shorter in F344, which has hyperresponsive negative feedback in the HPA axis. Ortiz et al. ${ }^{10}$ reported that LEW developed significant locomotor sensitization by chronic cocaine, but F344 did not show sensitization without chronic corticosterone pretreatment. Chronic MAP or cocaine possibly reduces the corticosterone level in F344; thus F344 might be resistant to the sensitizing effects of these drugs.

Corticosterone receptors can bind to their genes and potently downregulate transcription, while this effect is site-specific. Factors other than corticosterone receptor, which is ubiquitous, might be involved in this site-specific transcriptional control of corticosterone receptors. Although MAP-induced changes in GR and MR mRNA in F344 and LEW brain are region-specific, we observed increased GR and MR mRNA in F344 by acute and chronic MAP treatment, and decreased these mRNAs in LEW by chronic MAP. These results are partly consistent with a previous report, ${ }^{30}$ in which hippocampal GR mRNA of Sprague-Dawley rats is upregulated $24 \mathrm{hr}$ after acute AMP treatment, and downregulated by chronic AMP. Differences 
in experimental schedule and/or HPA axis response of each strain might be the reason for this discrepancy. As discussed above, decreased GR and MR mRNA by acute and chronic MAP in LEW might be caused by long-lasting elevation of corticosterone. Conversely, increased GR and MR mRNA by chronic MAP might reflect reduced corticosterone level in F344.

Among brain regions examined, we observed marked differences between F344 and LEW in their striatal GR and MR mRNA by chronic MAP: increase in F344, decrease in LEW. Striatal genes whose expression is regulated by corticosterone receptors might play an important role in susceptibility to behavioral sensitization.

\section{ACKNOWLEDGMENTS}

This study was partly supported by Grant-in-aid for Scientific Research (B)(2) \#10470200 (YN) and Health Sciences Research Grants for Research on Brain Science from the Ministry of Health and Welfare \#100109 (MS).

\section{REFERENCES}

1. Robinson, T.E. \& K.C. Berridge. 1993. The neural basis of drug craving: an incentive-sensitization theory of addiction. Brain Res. Brain Res. Rev. 18: 247-291.

2. Sato, M., Y. Numachi \& T. Hamamura. 1992. Relapse of paranoid psychotic state in methamphetamine model of schizophrenia. Schizophr. Bull. 18: 115-122.

3. Miller, K., J.D. Raese \& M. MorRison-Bogorad. 1991. Expression of heat shock protein 70 and heat shock cognate 70 messenger RNAs in rat cortex and cerebellum after heat shock or amphetamine treatment. J. Neurochem. 56: 2060-2071.

4. Goto, S., K. Korematsu, T. Oyama et al. 1993. Neuronal induction of 72-kDa heat shock protein following methamphetamine-induced hyperthermia in the mouse hippocampus. Brain Res. 626: 351-356.

5. Ali, S.F., G.D. Newport, R.R. Holson et al. 1994. Low environmental temperatures or pharmacologic agents that produce hypothermia decrease methamphetamine neurotoxicity in mice. Brain Res. 658: 33-38.

6. Cole, B.J., M. CAdor, L. Stinus et al. 1990. Critical role of the hypothalamic pituitary adrenal axis in amphetamine-induced sensitization of behavior. Life Sci. 47: 1715-1720.

7. Rivet, J.-M., L. Stinus, M. Le Moal et al. 1989. Behavioral sensitization to amphetamine is dependent on corticosteroid receptor activation. Brain Res. 498: 149-153.

8. Deroche, V., P.V. Piazza, S. Maccari et al. 1992. Repeated corticosterone administration sensitizes the locomotor response to amphetamine. Brain Res. 584: 309-313.

9. PiazZa, P.V., M. MARINElli, C. Jodogne et al. 1994. Inhibition of corticosterone synthesis by metyrapone decreases cocaine-induced locomotion and relapse of cocaine self-administration. Brain Res. 658: 259-264.

10. Ortiz, J., J.L. Decaprio, T.A. Kosten et al. 1995. Strain-selective effects of corticosterone on locomotor sensitization to cocaine and on levels of tyrosine hydroxylase and glucocorticoid receptor in the ventral tegmental area. Neuroscience 67: 383-397.

11. Evans, R.M. \& J.L. Arriza. 1989. A molecular framework for the actions of glucocorticoid hormones in the nervous system. Neuron 2: 1105-1112.

12. Yonehara, M., Y. Minami, Y. Kawata et al. 1996. Heat-induced chaperone activity of HSP90. J. Biol. Chem. 271: 2641-2645.

13. Nathan, D.F. \& S. LindQuist. 1995. Mutational analysis of Hsp90 function: interactions with a steroid receptor and a protein kinase. Mol. Cell. Biol. 15: 3917-3925.

14. Inanobe, A., K. TAkahashi \& T. Katada. 1994. Association of the beta gamma subunits of trimeric GTP-binding proteins with $90-\mathrm{kDa}$ heat shock protein, hsp90. J. Biochem. (Tokyo) 115: 486-492. 
15. CREeSE, I. \& S.D. IVERSEN. 1973. Blockage of amphetamine induced motor stimulation and stereotypy in the adult rat following neonatal treatment with 6-hydroxydopamine. Brain Res. 15: 369-382.

16. Miesfeld, R., S. RusConi, P.J. Godowski et al. 1986. Genetic complementation to a glucocorticoid receptor deficiency by expression of cloned receptor cDNA. Cell 46: 389-399.

17. Patel, P.D., T.G. Sherman, D.J. Goldman et al. 1989. Molecular cloning of a mineralocorticoid (type I) receptor complementary DNA from rat hippocampus. Mol. Endocrinol. 3: 1877-1885.

18. McGuire, J.A., L. Poellinger, A.C. Wikstrom et al. 1992. Cloning and regulation by glucocorticoid receptor ligands of a rat hsp90. J. Steroid Biochem. Mol. Biol. 42: 813-822.

19. Nudel, U., R. ZaKut, M. Shani et al. 1983. The nucleotide sequence of the rat cytoplasmic beta-actin gene. Nucleic Acids Res. 11: 1759-1771.

20. Reul, J.M.H.M., P.T. PearCe, J.W. Funder et al. 1989. Type I and type II corticosteroid receptor gene expression in the rat: effect of adrenalectomy and dexamethasone administration. Mol. Endocrinol. 3: 1674-1680.

21. Higashi, T., H. TaKeUchi, Y. Uemura et al. 1994. Differential induction of mRNA species encoding several classes of stress proteins following focal cerebral ischemia in rats. Brain Res. 650: 239-248.

22. Ulus, I.H., B.K. KIRAN \& S. OzKuRT. 1975. Involvement of central dopamine in the hyperthermia in rats produced by $d$-amphetamine. Pharmacology 13: 309-316.

23. Funahashi, M., H. KoHda, O. Hori et al. 1990. Potentiating effect of morphine upon $d$-methamphetamine-induced hyperthermia in mice. Effects of naloxone and haloperidol. Pharmacol. Biochem. Behav. 36: 345-350.

24. Carney, J.M., B. Tolliver, J.P. Carney et al. 1991. Selective effects of behaviorally active doses of methamphetamine on mRNA expression in the gerbil brain. Neuropharmacology 30: 1011-1019.

25. LU, D. \& D.K. DAS. 1993. Induction of differential heat shock gene expression in heart, lung, liver, brain and kidney by a sympathomimetic drug, amphetamine. Biochem. Biophys. Res. Commun. 192: 808-812.

26. Picard, D., B. Khursheed, M.J. Garabedian et al. Reduced levels of hsp90 compromise steroid receptor action in vivo. 1990. Nature 348: 166-168.

27. Yoshida, S., Y. Numachi, H. MAtsuOKa et al. 1998. Impairment of cliff avoidance reaction induced by subchronic methamphetamine administration and restraint stress: comparison between two inbred strains of rats. Prog. Neuropsychopharmacol. Biol. Psychiatry 22: 1023-1032.

28. CAmp, D.M., K.E. Browman \& T.E. Robinson. 1994. The effects of methamphetamine and cocaine on motor behavior and extracellular dopamine in the ventral striatum of Lewis versus Fischer 344 rats. Brain Res. 668: 180-193.

29. BudziszewsKa, B., L. JaworsKa-Feil \& W. LAson. 1996. The effect of repeated amphetamine and cocaine administration on adrenal, gonadal and thyroid hormone levels in the rat plasma. Exp. Clin. Endocrinol. Diabetes 104: 334-338.

30. Shilling, P.D., J.R. Kelsoe \& D.S. Segal. 1996. Hippocampal glucocorticoid receptor mRNA is up-regulated by acute and down-regulated by chronic amphetamine treatment. Brain Res. Mol. Brain Res. 38: 156-160. 